\title{
A framework to assess integration in flood risk management: implications for governance, policy, and practice
}

\author{
Lydia Cumiskey $^{1}, \underline{\text { Sally J. Priest }}^{1}$, Frans Klijn $^{2,3}$ and Meri Juntti $^{4}$
}

\begin{abstract}
Over decades the concept of integration has been promoted to enhance alignment between policy domains, and to manage trade-offs and maximize synergies across management practices. Integrated approaches have the potential to enable better outcomes for flood risk management (FRM) and society as a whole. However, achieving integration in practice is a recurring challenge, especially for FRM where multiple actors need to work together across fragmented policy domains. To disentangle this complexity of integration, a framework is proposed for assessing integration and identifying different degrees of integration. This framework is based on evidence from a literature review, 50 interviews with FRM-related professionals in England, and participant observation at 24 meetings relevant for FRM. The framework sets out the context of integration, assesses the governance capacity for integration through the strength of relationships between different types of actors (bridging, bonding, and linking) and the mechanisms (actor-, rule- and resource-based) that influence them, and the realization of integration in practice through knowledge, policies, and interventions. The framework is applied for FRM in England and used to identify degrees of integration: high, intermediate, low, and minimal. An important characteristic of the framework is the interconnectivity between the governance capacity and realization of integration. The framework provides further theoretical insights into the concept of integration, while offering an approach for researchers, policy makers, and practitioners to recognize current degrees of integration in FRM and identify the critical elements for improvement. It is recommended that further research and practice-based applications of the framework are completed in different geographical and institutional contexts. Specifically, such applications can create further understanding of the interactions and dependencies between elements of the governance capacity and realization of integration.
\end{abstract}

Key Words: assessment framework; governance; integrated flood risk management; integration; policy

\section{INTRODUCTION}

Integration is a term used frequently within flood risk management (FRM) policy making and practice because it involves multiple actors across sectors and levels of decision making (WMO 2009, Samuels et al. 2010). Integration is increasingly being promoted to manage "wicked problems," those complex policy problems subject to uncertainty, involving multiple actors with often diverging interests (Head 2008). These range from adapting to climate change and reducing disaster risk (Forino et al. 2015), to urban/spatial planning (Eggenberger and Partidário 2000, van Herk et al. 2011), or achieving sustainable development (Stafford-Smith et al. 2017). These complex challenges cannot be solved in isolation; and therefore an integrated approach to managing them is likely to prove to be more successful. Such an integrated approach focuses on understanding the interdependencies across sector objectives, and working within governance structures to manage them. Addressing challenges, such as FRM typically sitting outside one sector's remit, in a systematic way can ensure the wider causes and potential solutions are recognized. By doing so, integration aims to achieve more by jointly aligning objectives and policies, reducing duplication, managing trade-offs, and promoting synergy across interventions (Underdal 1980, Stead 2008, Candel and Biesbroek 2016).

However, integration has been criticized as acting as a mirage or an illusion of something that is desirable but difficult to achieve, for reasons such as time-consuming multiactor processes or blurred responsibility boundaries (Surridge and Harris 2007, Walker et al. 2014). Thus, attempts to achieve integration often fail (Williams and Sullivan 2009). Nevertheless, it is generally agreed that integration is needed to overcome siloed, fragmented (Gilissen et al. 2015), or disintegrated (Russel et al. 2018) approaches to policy making, which often result in negative sideeffects for other policy domains. Therefore, it is expected that some degree of integration is needed for actors to work collaboratively within existing governance structures to generate knowledge and policies that maximize synergies and manage trade-offs across FRM and sector-specific goals. Here we assume that integration is desirable because it has potential to yield better outcomes for FRM although is not easy to achieve.

There are a range of ways the term integration is being interpreted and used in research and practice. Examples include, describing the connections between actors at different levels or across sectors (Russel et al. 2018), science and policy (van den Hove 2007), social and technical perspectives (Brown and Damery 2002), or different modeling tools (Anselmo et al. 1996). Furthermore, integration is often an implicit goal when using other terms, for example, mainstreaming, emphasizing the connection of day-to-day activities (Russel et al. 2018), or intersectoral and interorganizational collaboration (Foster-Fishman et al. 2001). Additionally, integration is often used lightly, for example, stuck onto reports or research (e.g., Park et al. 2013) to increase their appeal without specifying the added value compared to regular policy making or management. Therefore, confusion can emerge to its actual meaning. To disentangle this complexity, we develop a framework to assess integration and identify different degrees of integration. The applicability of the framework is demonstrated for FRM in England, highlighting examples for

${ }^{1}$ Flood Hazard Research Centre, Middlesex University London, ${ }^{2}$ Deltares, ${ }^{3}$ Delft University of Technology, ${ }^{4}$ Department of Law and Politics, Middlesex University London 
different elements of integration and deriving the achieved degree of integration.

\section{CONCEPTUALIZING INTEGRATION}

To consider integration in the context of FRM, both the theoretical and practice-based constraints on achieving integration need to be considered. From the theoretical side, integration has been connected to the way actors balance their multiple overlapping interests to achieve a desired outcome, such as FRM (Underdal 1980, Stead 2008, Candel and Biesbroek 2016). In doing so, there are multiple integration challenges that actors can aim to address, e.g., across specific sectors. Furthermore, the understanding of the relationships between such actors and their governance arrangements has formed a central part of the theory surrounding integration, especially drawing on governance literature. Renn's (2008) definition of risk governance focuses on the complex web of actors, rules, conventions, processes, and mechanisms involved. Similarly, but placed in the context of flood risk governance, Alexander et al. (2016) emphasize the need for actor networks, rules, resources, discourses, and multilevel coordination mechanisms to pursue FRM. Other governance literature draws upon the importance of building relationships through theories of polycentric governance (Ostrom 2010), collaborative governance (Emerson et al. 2012), multilevel governance (Newig and Fritsch 2009), and network management (Agranoff and McGuire 2003). Embedded within this governance literature is the importance of mechanisms that strengthen or constrain actors' ability to cooperate, coordinate, collaborate (Keast et al. 2007, McNamara 2012), or enable integration (Stead 2008, Visseren-Hamakers 2015). The level of connectedness between these actors has been assessed by identifying the availability and strength of (bridging) mechanisms connecting actors, e.g., partnerships or regulations (Stead 2008, Gilissen et al. 2015). Furthermore, Koop et al. (2017) explain governance capacity as the key set of governance conditions that enable effective change, such as enabling integration. Reflecting on these theoretical insights, we identify one dimension of integration as the governance capacity for integration, derived through elements representing the strength of relationships between actors, and the mechanisms that influence them.

In addition to the governance capacity dimension, integration needs to be realized in policy and practice with tangible outcomes for FRM. Various discourses around integration have played a role in getting integration on policy agendas and demonstrating the practical need for more integration to achieve policy outcomes. As such, in Europe policies have driven more formalized approaches to integrated water resources management through the Water Framework Directive (WFD; 2000/60/EC) and integrated FRM through the Floods Directive (2007/60/EC). Similarly, global policies such as the Sustainable Development Goals call for policy coherence across sectors (OECD 2015). From a practical perspective, integration connected with management practices dates back to the 1980s for integrated river basin or water resources management (Glasbergen and Klijn 1991) as promoted by the Global Water Partnership (since the Dublin Principles in 1992). Over time, however, there have been significant changes in popularity of the term integration, largely because of its ambiguity. For FRM these variations include sustainable FRM, e.g., the IMRA-SPONGE project (Hooijer et al. 2004), integrated flood management from the World Meteorological Organization concept paper (WMO 2009), integrated FRM within the Floodsite Project (Samuels et al. 2010), and toward comprehensive FRM (Klijn and Schweckendiek 2013). Similarly, these management approaches argue the importance of taking a systems approach to FRM, looking at the catchment as a whole to understand the positive and negative influences of interventions accounting for the spatial and temporal complexity across boundaries (Hall et al. 2006, WMO 2009, van Herk et al. 2015, APFM 2017). Additionally, emphasis is placed on selecting a mix of interventions that manage trade-offs and maximize the multiple benefits between objectives (GWP 2000, WMO 2009, Sayers et al. 2014, Challies et al. 2016, APFM 2017). Furthermore, it is recognized that the generation of joint knowledge or evidence bases across multiple actors forms a critical step in helping actors to work together to develop policies and implement interventions (Underdal 1980, Newig and Fritsch 2009, Evers et al. 2012, Challies et al. 2016). Combining these insights from integration in practice we identify the realization of integration as another dimension of integration, derived through the joint, aligned, or integrated knowledge, policies, and interventions generated.

The next point to emphasize is the dynamic nature of these dimensions of integration and how the associated elements interact with one another, an important characteristic of integration also identified by Candel and Biesbroek (2016). This is conceptualized in Figure 1 and forms the basis for the assessment framework. The inner-most circle (dark grey) represents the integration challenge that actors' work toward achieving in a particular context, while the next inner circle (light grey) represents the governance capacity for integration including the relationships between the actors and their influencing mechanisms. The outer two circles represent the realization of integration through policies and interventions (black-grey circle), and knowledge (inner white circle), which acts as the interface between the capacity and realization of integration. Importantly, the flow between each of the elements is demonstrated by multiple arrows. For example, strengthened relationships can lead to improved mechanisms and continuously influence the development of integrated knowledge, policies, and interventions as one informs the other. Furthermore, the implementation of joint plans can lead to more multibenefit schemes being implemented, which further improves actor relationships and drives improvements to mechanisms. In contrast, limited governance capacity for integration can jeopardize the ability to deliver integrated polices or interventions for a particular challenge. Overall, we consider that the elements representing the capacity and realization of integration need to be assessed sideby-side because of their interconnected nature. Other conceptualizations of integration using, e.g., a horizontal continuum (Keast et al. 2007, McNamara 2012), a triangle (Stead 2008), or a prism (Parkes et al. 2010), do not emphasize these dynamics. Details on how each of the dimensions and associated elements are assessed within the framework, their interconnectivity with one another, and how they are used to identify degrees of integration, are explained in later sections of the paper.

\section{METHODOLOGY}

An assessment framework is developed based on the conceptualization of integration emerging from a literature review, along with in-depth interviews, participant observation, and document review for FRM in England. The data collection 
thus included in-depth interviews between November 2017 and March 2019 with professionals in England at the national level $(n=15)$ and at the local level $(n=35)$, in two case study areas in the Anglian and Yorkshire regions. These professionals ranged from those working directly on FRM issues (including but not limited to Environment Agency [EA], lead local flood authorities [LLFA], internal drainage boards [IDB]), to sector-specific actors (including but not limited to infrastructure providers, water companies, environmental NGOs). The key themes in the interviews broadly covered the elements of integration identified in the literature review. This included the strength of relationships between FRM key actors and others, the influence of mechanisms, e.g., partnerships, regulations, and funding, knowledge development, alignment between FRM and sectorspecific policies, and interaction between FRM and sectorspecific interventions.

Fig. 1. Conceptualization of the interconnectivity between the dimensions and elements of integration.

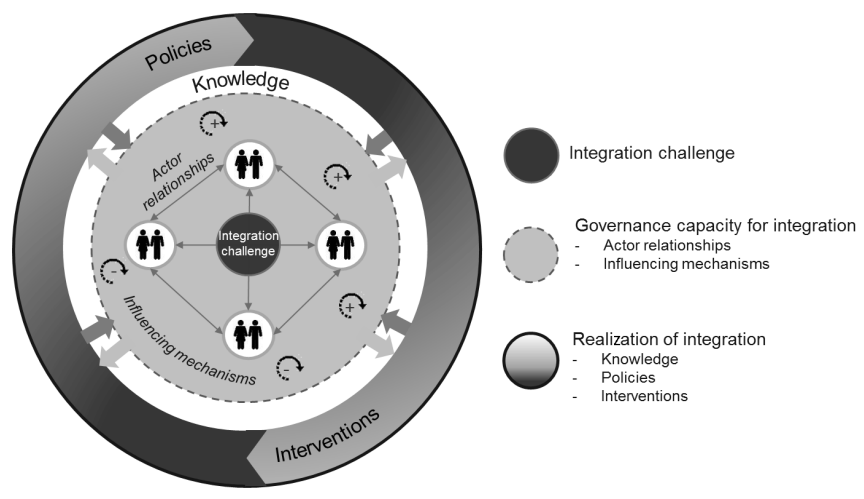

In addition to the interviews, FRM related meetings were attended $(\mathrm{n}=24)$ to gain further insights into working arrangements between actors. These included multistakeholder partnership meetings at the national level, e.g., national FRM stakeholder forum led by the EA, at the regional level, e.g., regional flood and coastal committees (RFCC), and at the local level, e.g., local FRM partnerships led by LLFAs. These primary data were further supplemented with secondary data including review of FRM specific plans $(n=15)$, e.g., Regional Flood Risk Management Plans, Local Flood Risk Management Strategies, and sector specific plans $(n=20)$, e.g., National 25 Year Environment Plan, Regional River Basin Management Plans, and Local (development) Plans. These plans were selected based on those identified in the interviews and meetings both locally and nationally, and to ensure broad coverage of sectors. Furthermore, additional guidance documents, available meeting minutes, and associated documents $(n=35)$ were reviewed.

The interviews and observation notes were transcribed, and coded using thematic analysis (Fereday and Muir-Cochrane 2006). The research followed a mix of deductive and inductive coding. Although the elements of integration were identified from the literature (deductively), they were then further verified based on the inductive coding of the evidence collected. Similarly, the indicators for assessing each of the elements were initially scoped from the literature but then further refined based on inductive coding.

\section{FRAMEWORK FOR ASSESSING INTEGRATION}

\section{Integration context and challenge}

The starting point for integration is jointly working toward common goals, such as FRM, as a means to support society as a whole. Considering that flood risk governance arrangements will be fragmented in different ways (Gilissen et al. 2015), some form of integration is needed between different sectors, types of flood risk, and across different boundaries, e.g., geographical, administrative, or catchment (Underdal 1980, Stead 2008, WMO 2009, McNamara 2012). However, this challenge can be approached in an overarching or piecewise manner. Therefore, it is important to understand the specific integration challenges because they will likely vary from one governance context to another.

To understand the integration challenges for English FRM, we first briefly introduce this contextual background. In England there is a broad range of actors responsible for different aspects of FRM identified as the risk management authorities (RMAs), as specified under the Floods and Water Management Act (UK Government 2010). These actors include the EA, based regionally and nationally, responsible for managing flooding on main rivers; LLFAs responsible locally for ordinary water courses and surface water; IDBs responsible for ordinary water courses (where required); water companies responsible for sewer flooding; and highway authorities responsible for surface water runoff from highways. FRM in England engages multiple strategies to manage flood risk, including preventing new risk (spatial planning), reducing existing risk (flood defense and mitigation), and managing residual risk (preparedness, response, and recovery) using the categorization from the United Nations Office for Disaster Risk Reduction (UNISDR 2015) and Hegger et al. (2016). The key cross-cutting policy sectors with FRM include the environment sector also led by the EA, the water sector (resources, wastewater, drainage) falling mainly under water companies, emergency management led by the Cabinet Office under the Civil Contingencies Act, along with housing, economic growth, infrastructure, and agricultural sectors, all influencing FRM.

Given the fragmentation between sectors, both for those responsible for different sources of flood risk, different FRM strategies, and wider sector-specific responsibilities, there are multiple layers that require integration for FRM in England. Figure 2 approximately highlights the potential areas for integration given the different FRM strategies (central circle) and sector-specific policy domains (outer circles) for FRM in England, as well as the extent of the influence (size of circle). For example, preventing future risk was found to overlap with housing, infrastructure development, and economic development at large while reducing existing risk was found to overlap with water supply (e.g., multipurpose reservoirs) and biodiversity preservation (e.g., river dredging regimes). Many other overlaps are also possible but difficult to present in one figure (e.g., between agriculture and risk reduction due to the provision of flood storage areas). Any one of these overlaps, or combinations thereof, can form integration challenges. Additionally, an integration challenge can be seen when managing different sources of flood risk. For example, aligning the work of the EA on main rivers, IDBs on ordinary watercourses, and water companies for sewer flooding. 
Fig. 2. Visualization of possible areas for integration between flood risk management (FRM) and other sector-specific policy domains, approximated for England.

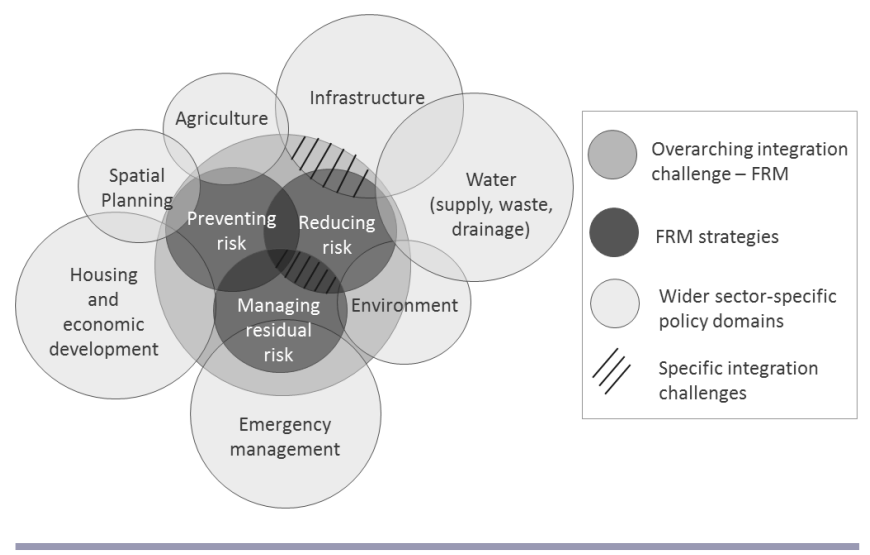

In practice, certain integration challenges for FRM may be prioritized over others because of urgency, e.g., recent floods, local conditions, e.g., catchment characteristics and types of flood risk, or combined institutional responsibilities, e.g., water companies in England are responsible for surface water runoff from sewers and water supply. Therefore, an assessment of integration could be in the form of a detailed assessment for a specific integration challenge, e.g., across specific sectors or FRM strategies, or a more broad overarching assessment across multiple sectors, sources of flood risk, and FRM strategies. Considering the wide range of integration challenges for FRM in England, the interest and willingness of the FRM community to enable integration across multiple sources of flood risk and sectors was strongly identified. Therefore, the assessment framework could be applied in more detail for specific integration challenges. However, for the purpose of this paper, broader insights on integration for FRM in England are provided to demonstrate the general applicability of the framework.

\section{Governance capacity for integration}

\section{Actor relationships}

The governance capacity for integration was found to be strongly related to the number of actors involved and the strength of their relationships (Gilissen et al. 2015, Candel and Biesbroek 2016). Therefore, based on the literature and the results from the interviews, we propose mapping out the different actors and identifying if they have strong, medium, or weak relationships focusing on two key indicators: (1) mind-set alignment and (2) communication intensity. Furthermore, it is important to assess the strength of the relationship from both actors' perspectives (Granovetter 1973, Reed et al. 2009). We define actors as organizations or teams within organizations if multiple roles exist, rather than the individuals. Instead of identifying trust as an indicator itself, here it is assumed that when actors have aligned mind-sets and strong interaction then they will build trust with one another.

First, literature highlights that the way the different actors perceive or frame the problem (causal beliefs, cognitions, or frames of reference) and their values (norms, interests, and purposes) will influence their ability to work together (Underdal 1980, Keast et al. 2007, McNamara 2012, Thissen and Walker 2012, Candel and Biesbroek 2016). This was evident in the interviews with FRM professionals in England who reinforced the importance of aligning mind-sets and building shared understanding of FRM between key actors within FRM and across sectors, before relationships could grow. Generating this shared mind-set was found to be dependent on the knowledge the actors have on the system interdependencies, their ability to address the problem, the organizational culture, and their willingness to work together. The second indicator found to affect relationship strength was the interaction and communication between actors, as identified in the literature by Candel and Biesbroek (2016) and Gilissen et al. (2015). The findings from the interviews and meeting observations with FRM actors indicated that the strength of the interaction was dependent upon the type of communication, either one way or two-way and the level of formality, the frequency and duration of communication, e.g., staff availability for interaction at meetings or bilateral exchange, and the resulting quality of the interaction, e.g., sharing data and resolution of issues. To highlight an example of both indicators for FRM in England, a water company (in the Anglian region) was found to have a clear understanding of system dependencies combined with a proactive organizational culture, and willingness to work in partnership, alongside improved communication through identified contact points and attendance at partnerships. Together, as evidenced by both the water companies and the other RMAs, this was found to enable them to build strong relationships with partners and to build trust, in particular with the LLFAs and the EA.

Next, different relationship types are distinguished, bonding, bridging, and linking, as used by Gittell and Vidal (1998) and Szreter and Woolcock (2004) for identifying social capital. For relationships between actors responsible for FRM, they are expected to need more bonding relationships because they are similar in some form (Putnam 2000). In comparison, bridging relationships will be needed for connecting FRM and sectorspecific objectives because they are dissimilar in a demonstrable fashion (Szreter and Woolcock 2004), e.g., representing different sector interests. Linking relationships are needed when connecting across spatial boundaries, e.g., national, regional, local, to individuals who have power over them (Szreter and Woolcock 2004), e.g., local authorities and communities. In the case of FRM in England, the interviews and meeting observations showed that the bonding relationships between RMAs have greatly improved since the implementation of the Floods and Water Management Act 2010 (UK Government 2010) and the move toward partnership working, in particular between the EA, water companies, IDBs, and LLFAs. The bridging relationships were found to vary for different sectors, e.g., for environment the push toward natural flood management (NFM) and the catchment-based approach helped to bring together environmental NGOs and RMAs. However, there remains a bigger gap to bridge between those working on housing and infrastructure development with FRM. The linking relationships between the community and RMAs were found to be dependent on the presence and strength of flood groups and local community leadership. 
Fig. 3. Overview of actor-, rule-, and resource-based mechanisms.

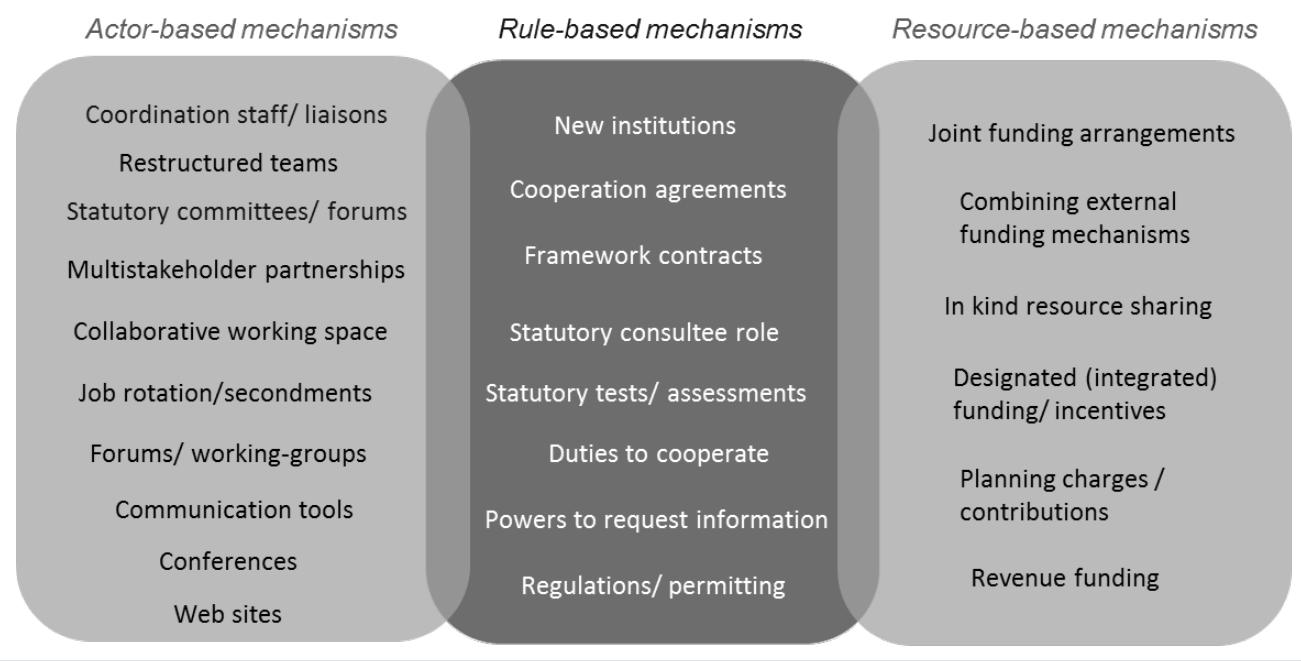

\section{Influencing mechanisms}

The presence and strength of different mechanisms will positively or negatively influence the strength of actor relationships, and vice versa (Stead 2008, Gilissen et al. 2015), and thus the governance capacity for integration. These mechanisms are named and characterized differently across the literature: bridging mechanisms grouped into transfer, coordination, and cooperation mechanisms (Gilissen et al. 2015); policy cooperation, policy coordination, and policy integration mechanisms (Stead 2008); and procedural instruments that facilitate coordination (Candel and Biesbroek 2016). Similar across these different characterizations is an increasing scale through which different mechanisms support different levels of joint working across actors. However, the interpretation of the terms coordination and cooperation can cause confusion (McNamara 2012), thus a more simplified descriptive categorization was sought. The policy arrangements approach (Arts et al. 2006) distinguishes actors, resources, rules of the game, and discourses, and emphasizes the interconnected nature between them. Therefore, the simplified categorizations of actor-, rule-, and resource-based mechanisms were found to be useful to delineate such categorizations, as shown in Figure 3. However, discourses were not included as a type of mechanism because, although they can influence integration over time, they are less tangible than actors, rules, and resources.

Actor-based mechanisms are identified as those that improve actors' interaction, communication, and knowledge exchange. As depicted in Figure 3, these include intergovernmental committees, working groups or coordinating councils (Agranoff 2006, Stead 2008), multistakeholder partnerships or platforms (Pattberg and Widerberg 2016), conferences (Stead 2008), collaborative working arrangements (Stead 2008), human resource policies such as secondments or job rotation (Stead 2008), joint planning processes or working groups (Freude am Fluss 2007), crosscutting units or interdepartmental teams (Stead 2008, Candel and Biesbroek 2016), and individual staff positions or coordinators who act as boundary spanners (Agranoff 2006, Williams 2011). Examples of all the above actor-based mechanisms were identified for FRM in England either through the interviews or through observation in meetings. Here, however, there is only space to detail the more interesting examples. The local FRM partnerships led by LLFAs were found to be very successful at aligning mind-sets across RMAs and building strong relationships, however, there is still room to improve the breadth of members included to align different objectives and actions, for example by also including local enterprise partnerships (LEP), catchment partnerships, and community representatives. Similarly, the research found that statutory RFCC offered a good platform for knowledge exchange between actors but have potential to be further improved by drawing connections with other local partnerships and groups, as identified by Benson et al. (2016).

Rule-based mechanisms are identified as those that determine how actors must interact, for example, powers to request information or duties to cooperate (Gilissen et al. 2015), statutory consultation requirements (Gilissen et al. 2015, Candel and Biesbroek 2016), statutory tests/impact assessments (Stead 2008, Gilissen et al. 2015), cooperation agreements or memorandums of understanding (Agranoff 2006), framework contracts, and standards/regulations setting (Candel and Biesbroek 2016). Again, these mechanisms were identified for FRM in England. As a result of the Flood and Water Management Act (UK Government 2010) new rules were established for FRM, including redistributing roles and responsibilities for different types of floods. LLFAs, for example, now act as a statutory consultee on planning decisions in areas at risk of surface water flooding, and formalizing interaction between actors including a duty to cooperate. However, it was identified by some interviewees that additional RMAs need such a statutory role to influence development. Through interviews with IDBs and the EA, the public sector cooperation agreements were identified as a very useful mechanism to facilitate shared maintenance programs across main rivers and ordinary watercourses. Consultation processes ensure some form of multiactor engagement is completed for policy making, although the design and resulting effectiveness of such processes can vary (Newig and Fritsch 2009). 
A positive example we observed as having an intensive multistakeholder consultation, is the National Flood and Coastal Erosion Risk Management Strategy draft published in August 2019 (Environment Agency 2019). It engaged 150 individuals across 90 organizations in different working groups before the online formal public consultation, which received 400 external responses.

Resource-based mechanisms are identified as the funding arrangements that help actors to implement joint actions in the form of operational activities, projects, or programs of work, including their ability to hire and train staff, for example, overarching funding programs (Stead 2008), combined external funding sources, financial incentives such as tax deductions (Candel and Biesbroek 2016), financial contributions, e.g., from developers, or in-kind resources sharing (such as staff time). For FRM in England, the interviews showed that "partnership funding" (Environment Agency 2012) was a successful mechanism in improving relationships between the EA, LLFAs, IDBs, and water companies through the process of jointly defining and funding projects. However, the mechanism currently fails to sufficiently recognize the benefits for infrastructure, business, and the environment, thus failing to build relationships across those sectors. Furthermore, the misaligned timescales and criteria (or "strings") for obtaining external funding such as the "economic growth funding," were found to hinder joint action between FRM actors and those dealing with economic growth, i.e., LEP. Another local funding mechanism, the local levy, collated across all local authorities in the RFCC area was found to offer flexibility to fund smaller projects, e.g., for property resilience, and to hire individuals to work in partnership to develop funding bids or portfolios of projects. The nationally allocated funding of $£ 15 \mathrm{~m}$ for NFM in 2017 (Defra 2017) was recognized by interviewees to strongly improve relationships between LLFAs, EA, environmental NGOs, and universities to generate new knowledge and jointly test NFM interventions. Furthermore, the presence and strength of mechanisms was found to vary depending on local conditions. For example, flood events in Leeds led to additional national funding being available to support local FRM partnerships at the catchment scale.

This interconnected nature of the actor-, rule-, and resourcebased mechanisms links to the broader agency-structure debate (Hay 1995, Williams 2011) whereby there is an interplay between individual agency and the more formalized mechanisms through which they operate. For example, the importance of the newly formed water company flood risk coordinators (in the Anglian region) was found to be pivotal in building stronger relationships across RMAs to utilize partnership funding opportunities and thus the delivery of joint surface water flood management schemes. This is demonstrated in Figure 4 (solid arrows). Furthermore, the proactive and motivated characteristics of these coordinators further enhanced their capacity to drive additional improvements, for example, through establishing a new regional LLFA partnership, which then further improved relationships between actors, as did the implementation of joint schemes (shown by the dashed arrows in Figure 4). This demonstrates the interplay between individuals and their ability to influence positively other relationships by utilizing mechanisms at their disposal or developing new ones.
Fig. 4. Demonstration of the interplay between mechanisms and relationships.

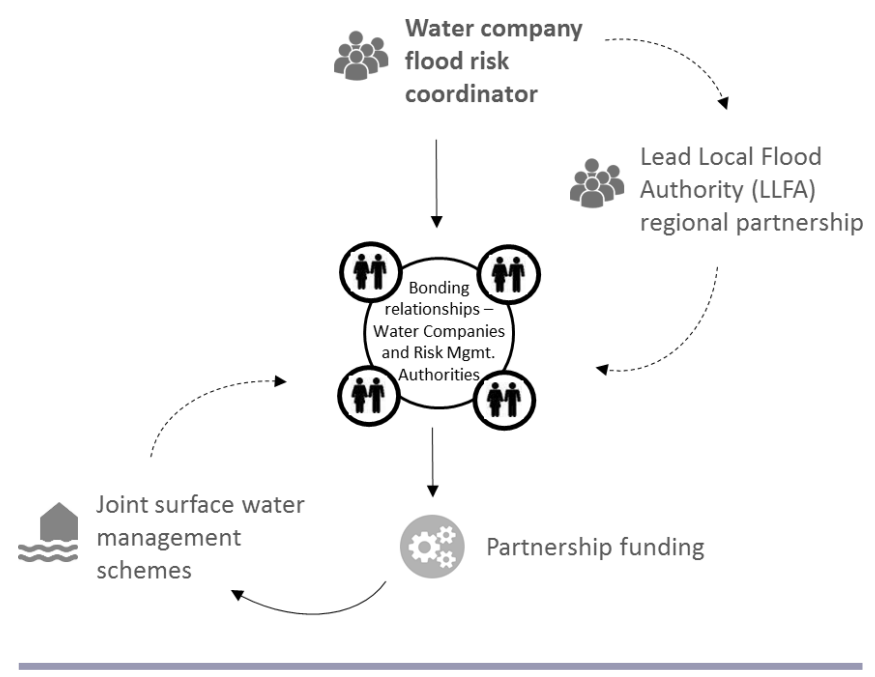

\section{Realization of integration}

Knowledge

Extracting and developing knowledge across actors acts as a stepping stone to develop a common view of the problem to aid joint-decision making (Underdal 1980, Newig and Fritsch 2009, Challies et al. 2016). It can improve communication exchange between actors, offer opportunities to bring new actors on board, and help to align mind-sets for future plans and projects (Evers et al. 2012). Therefore, the process of developing such knowledge builds capacity for integration, however, we focus on knowledge as a tangible output for the realization of integration in practice but recognize the influence on building capacity for integration. As identified through the interviews, joint knowledge in the sphere of FRM is recognized as collaborative modeling, baseline studies and assessments, e.g., flood mapping/risk assessments, societal cost-benefit analysis (CBA), procedural frameworks/protocols, or jointly developed guidance methodologies on implementing policies or interventions. The following indicators are identified to assess the strength of the knowledge available to support integration.

- Presence of knowledge jointly developed by and accessible to multiple actors;

- Use of the knowledge to influence other elements (relationships, mechanisms, policies, interventions).

The importance of developing risk models jointly by multiple actors was identified during the interviews where water companies, IDBs and the EA, and universities were found to work together to complete investigations to develop joint business cases. Another example is the Working with Natural Processes evidence directory, which was codeveloped with the research community, other public bodies, and NGOs to build evidence to support the implementation of NFM interventions in England and Wales, thus influencing the realization of integration in practice (Environment Agency 2017). Joint knowledge was also found to be a result of learning from a history of implementing specific 
policies or interventions by multiple actors, for example, the SuDS (Sustainable Drainage Systems) manual in England (Woods-Ballard et al. 2015) which supports further implementation of SuDS interventions. However, the results from the interviews showed that there are still some knowledge gaps to align FRM and environmental objectives, such as the lack of agreed methodologies for performing cross-sectoral societal CBA.

\section{Policies}

Policies can range from plans at different boundaries, e.g., geographical, administrative, and catchment, or programs of planned work. Policies that are aligned and coherent both across FRM related policies, e.g., different sources of flood risk, from national to local levels, and with other sector-specific policies are more integrated. The following indicators were identified to assess the strength of policies to enable integration, demonstrated below through examples from FRM in England.

- Availability of new/joint plans (Underdal 1980, Candel and Biesbroek 2016);

- Alignment of objectives and interventions across plan boundaries (Underdal 1980, OECD 2015, Candel and Biesbroek 2016);

- Consistency of time frames for preparation, monitoring, and renewal (Stead 2008, OECD 2015).

For the first indicator, relating to the availability of joint or overarching plans, from a FRM perspective, new integrated catchment-based FRM plans have been developed on a case-bycase basis in England usually after significant flood events, for example, the Cumbria Flood Action plan emphasizing a catchment-based approach and partnership with communities (Environment Agency 2016). Whereas, from a sector-specific perspective, the Network Rail Weather Resilience and Climate Adaptation Strategy (2017-2019) and Route Climate Adaptation Plans (Network Rail 2017) were identified as a good example of a specific plan integrating FRM objectives with rail infrastructure planning. Additionally, from the environment sector, the national 25 Year Environment Plan(HM Government 2018) was identified as a good example of a national overarching plan that strongly emphasizes the importance of aligning environment and FRM objectives nationally and locally.

The second indicator relates to the alignment of objectives and interventions across FRM and sector-specific plan boundaries, e.g., administrative, geographical, catchment, flood source. In particular sector-specific plans will likely have different boundaries, e.g., economic or growth areas in comparison to catchments and therefore extra effort is needed to consider the overlaps in objectives and interventions. The extent of alignment between FRM and sector-specific plans was found to be limited by the engagement of representative actors, e.g., in local FRM partnerships or the RFCC meetings. In England the water companies were found to actively engage with LLFAs and the EA to identify opportunities for joint interventions in their asset management plans, for example, contributing to a flood alleviation scheme that also protects water company assets and is informed by joint studies and funded jointly by local authorities and water companies.
For the third indicator, the consistency of the time frames for preparation, monitoring, and renewal, overall the evidence from the interviews showed the challenges to connect the array of plans especially considering their scattered, "out of sync" time frames. For example within FRM, the local FRM strategies and regional FRM plans were prepared under different time lines making it difficult to align monitoring efforts. However, where time frames are more consistent, as is the case with Water Framework Directive and Floods Directive related plans, interviews with the EA revealed that the upcoming revisions of the regional FRM strategies and river basin management plans aim to be more strongly aligned compared to existing plans.

\section{Interventions}

Interventions can range from small-scale actions to large-scale investment projects or maintenance programs. Interventions that actively account for the interactions with other FRM and sectorspecific objectives and interventions are more integrated. The following indicators are identified to assess integration across interventions, demonstrated below through examples from FRM in England.

- Maximized synergy (WMO 2009, Challies et al. 2016);

- Managed trade-offs and side-effects (WMO 2009, Sayers et al. 2014, APFM 2017);

- Maximized efficiencies (Sayers et al. 2014, Alexander et al. 2016).

Depending on the integration challenge, synergies should be maximized across FRM and sector-specific interventions. The interviewees identified the importance of FRM actors working together to capture synergies within FRM interventions by looking across different sources of flood risk, FRM strategies (prevention, reduction, residual risk), temporal scales (e.g., strategic planning, implementation/operation, and incident response), and different spatial boundaries (e.g., catchment, administrative, geographical). If there is a more diverse range of FRM interventions, as is the case in England, then there will be more opportunities to capture synergies between interventions. For example, flood defense schemes combining property level resilience (PLR) measures and utilizing early warning systems can more cost-effectively manage flood risk, as shown in the Leeds flood alleviation scheme (FAS). Additionally, FRM projects were found to support the delivery of wider objectives, for example, the Leeds FAS that helped to unlock economic growth and jobs. Furthermore, in Cumbria building a flood storage reservoir along with a nature reserve area as part of the Thaka Beck FAS helped to unlock additional environmental and amenity benefits. Interviews with sector-specific actors identified opportunities to unlock additional benefits for FRM from sector-specific interventions. For the infrastructure sector, the A14 road improvement project led by Highways England, funded PLR measures for households along the route through their Legacy Fund. Furthermore, catchment-sensitive farming approaches and river restoration projects were found to be useful interventions to reduce siltation and increase storage capacity of the river, thus reducing flood risk.

The next indicator relates to addressing the trade-offs (and negative side-effects) between different FRM and sector-specific interventions. If one intervention is implemented it may mean 
that something else cannot be achieved, i.e., trade-off, or that there is an unintended consequence, i.e., negative environmental, social, or economic side effects. Compensatory or counterbalancing interventions may be required to manage any increases in risk or reduce the consequences. Similar to the synergies, these need to be managed across sources of flood risk, FRM strategies, temporal scales, and spatial boundaries, depending on the integration challenge. FRM interventions will need to mitigate or compensate any negative side effects with other sectors, e.g., by including a fish pass and replanting of trees cut down as part of a flood scheme, as identified in the Leeds FAS. Additionally, any sector-specific projects, such as road improvements, will need to mitigate any risk increase they might cause to neighboring homes, e.g., from increased highway runoff or a new bridge crossing the river at a critical point, as identified in the A14 road improvement project in England. Large housing and transport development projects need to be carefully planned to ensure they do not increase flood risk. For example, the Cambridge-Oxford Arc project aiming to deliver 1 million homes and transport improvements (East-West railway and Cambridge-Oxford Expressway) is constrained by large proportions of environmentally protected and/or flood prone land (MHCLG 2019).

The final indicator identified is the time and cost (in)efficiencies that actors can gain or lose from working together to implement interventions in an integrated way. These were found to range from cost savings such as closing a road for multiple purposes, or larger cost savings reducing the overall cost of the intervention from using the same contractors and consultants to implement the interventions. Other savings identified included sharing of maintenance or a reduction in the staff cost of developing a business case because another actor takes the lead. However, the transaction costs, e.g., time spent at meetings or money spent doing integrated assessments, can also result in inefficiencies, but interviewees agreed that these are likely to pay off in the long run.

\section{IDENTIFYING THE DEGREE OF INTEGRATION}

The assessment framework explained how each of the elements of integration can be assessed, next we identify four degrees of integration: high, intermediate, low, and minimal. Overall, characterizing these degrees of integration aims to demonstrate the varied nature through which integration can evolve and the potential movement between different degrees of integration by addressing different elements. Table 1 details each degree of integration by explaining the status of each of the elements for the governance capacity and realization of integration. These were distinguished by building upon the evidence collected on each of the elements for FRM in England and utilizing examples of stronger and weaker parts of each element as described by the interviewees. Each degree of integration is described herein and how it relates to each element and the associated indicators.

High integration is expected to have strong relationships between actors (bridging, bonding, and linking) with positively influencing actor-, rule-, and resource-based mechanisms in place that are continuously being tested and improved. There is strong presence of joint knowledge that is used to influence other elements of integration. FRM and sector-specific policies have strong alignment and new joint policies available where necessary. Multiple benefits, managed trade-offs, and maximized efficiencies are gained across most FRM and sector specific interventions. This degree of integration was distinguished through the research because it represents the direction that many FRM actors in England identified as striving toward, a situation where they could systematically align objectives and policies to deliver multiple benefits without any mechanisms acting as significant barriers.

Intermediate integration is expected to have strong to moderate bonding relationships with good communication and aligned mind-sets but there is room to improve the moderate bridging and linking relationships. The implementation of actor-, rule-, and resource-based mechanisms are expected to improve actors' ability to work toward integration, but some mechanisms still negatively influence their ability to realize integration in practice, e.g., funding "strings," limited participation in partnerships. Knowledge is jointly developed by actors and used as an evidence base to influence policies and interventions. FRM policies are expected to have strong alignment (objectives, interventions, time lines) but opportunities remain to improve alignment with sectorspecific policies. Some FRM and sector-specific interventions are expected to deliver multiple benefits, manage trade-offs, and gain efficiencies; however, it is not yet business as usual. The previous discussion assessing the elements of integration justify how FRM in England can be generally characterized at this degree of integration. Unfortunately, it is not possible within the limits of the paper to do a more detailed assessment of more specific integration challenges for FRM in England.

Low integration is expected to have moderate bonding relationships and weak to moderate bridging and linking relationships, where perspectives are starting to align. This degree of integration is expected to have some positive and negatively influencing mechanisms available but require adjustment to better support integration. Some presence of joint knowledge is expected but with limited use to influence other elements of integration. FRM policies are expected to have moderate alignment compared to weak alignment with sector-specific policies. FRM interventions are expected to focus on efficiency gains for "easy wins" and to manage critical trade-offs but only minor testing of multibenefit interventions across sectors. Insights into this degree of integration were identified from the interviews and observation at meetings where FRM actors discussed how they evolved into working more closely with partners to realize integration through the implementation of the various mechanisms, including those in the Flood and Water Management Act (UK Government 2010). When considering FRM in England, this can be considered the baseline degree of integration through which a higher degree was subsequently achieved.

Minimal integration is expected to have weak bridging and linking relationships where actors have competing perspectives and insufficient or poor quality mechanisms to enable interaction. Bonding relationships are expected to be moderate to weak as actors have low levels of interaction. However, weak alignment is expected within FRM and sector-specific policies and attempts to integrate FRM and sector-specific interventions are expected to be unsuccessful, time-consuming, and costly. This degree of integration was distinguished based on insights into the poor examples of integration provided from interviewees. Some interviewees discussed how they did not want to "go backwards" 
Table 1. Assessment table for identifying the degree of integration.

\begin{tabular}{|c|c|c|c|c|c|}
\hline \multirow{2}{*}{$\begin{array}{l}\text { Degree of } \\
\text { integration }\end{array}$} & \multicolumn{2}{|c|}{ Governance Capacity for Integration } & \multicolumn{3}{|c|}{ Realization of Integration } \\
\hline & Actor relationships & Influencing mechanisms & Knowledge & Policies & Interventions \\
\hline $\begin{array}{l}\text { High } \\
\text { integration }\end{array}$ & $\begin{array}{l}\text { Strong bonding, bridging } \\
\text { and linking relationships. } \\
\text { Shared mind-set (proactive } \\
\text { organizational culture, } \\
\text { willingness to work } \\
\text { together, and } \\
\text { understanding of } \\
\text { interdependencies). } \\
\text { High communication } \\
\text { intensity (very frequent, } \\
\text { effective two-way } \\
\text { interaction). }\end{array}$ & $\begin{array}{l}\text { (+) Actor-based } \\
\text { mechanisms in place and } \\
\text { effective (diverse actors } \\
\text { involved, benefits outweigh } \\
\text { costs, resourced proactive } \\
\text { staff). } \\
(+) \text { Sufficient rules in place } \\
\text { and enforced. } \\
(+) \text { Variety of funding } \\
\text { mechanisms accessible. }\end{array}$ & $\begin{array}{l}\text { Strong presence of } \\
\text { knowledge (e.g., } \\
\text { assessments, studies, } \\
\text { datasets), developed by } \\
\text { and shared across a } \\
\text { variety of actors, and } \\
\text { used to influence other } \\
\text { elements (policies, } \\
\text { interventions, } \\
\text { mechanisms, and } \\
\text { relationships). }\end{array}$ & $\begin{array}{l}\text { Some new joint plans } \\
\text { exist. } \\
\text { Strong alignment between } \\
\text { different flood risk } \\
\text { management (FRM) } \\
\text { plans (sources flood risk, } \\
\text { temporal scale, spatial } \\
\text { boundaries). } \\
\text { Strong alignment between } \\
\text { FRM and sector-specific } \\
\text { plans (objectives, joint } \\
\text { interventions, time lines, } \\
\text { boundaries). }\end{array}$ & $\begin{array}{l}\text { Strong integration between } \\
\text { FRM interventions and } \\
\text { most sector-specific } \\
\text { interventions. Systematically } \\
\text { capture multiple benefits, } \\
\text { manage trade-offs, and gain } \\
\text { efficiencies. }\end{array}$ \\
\hline $\begin{array}{l}\text { Intermedi- } \\
\text { ate } \\
\text { integration }\end{array}$ & $\begin{array}{l}\text { Strong-moderate bonding, } \\
\text { and moderate bridging and } \\
\text { linking relationships. } \\
\text { Mostly shared mind-sets } \\
\text { (general willingness to } \\
\text { work together and manage } \\
\text { interdependencies but some } \\
\text { barriers exist). } \\
\text { Increasing communication } \\
\text { intensity (frequency and } \\
\text { effectiveness improving). }\end{array}$ & $\begin{array}{l}(+) \text { Actor-based } \\
\text { mechanisms in place but all } \\
\text { not fully effective (e.g., } \\
\text { poor diversity of actors, } \\
\text { insufficient staff). } \\
\text { (+/-) Rules available but } \\
\text { some are not well designed } \\
\text { or enforced. } \\
\text { (+/-) Some joint-funding } \\
\text { available but some } \\
\text { limitations and "strings" } \\
\text { attached when accessing } \\
\text { wider (sector) funding. }\end{array}$ & $\begin{array}{l}\text { Strong to moderate } \\
\text { presence of knowledge } \\
\text { (e.g., assessments, } \\
\text { studies, datasets), most } \\
\text { developed by and } \\
\text { shared across a variety } \\
\text { of actors, and used to } \\
\text { influence other } \\
\text { elements. }\end{array}$ & $\begin{array}{l}\text { Some new joint plans } \\
\text { exist. } \\
\text { Strong-moderate } \\
\text { alignment between } \\
\text { different FRM plans } \\
\text { (sources flood risk, } \\
\text { temporal scale, spatial } \\
\text { boundaries). } \\
\text { Moderate alignment } \\
\text { between FRM plans and } \\
\text { some sector-specific plans } \\
\text { (objectives, interventions, } \\
\text { time lines, boundaries). }\end{array}$ & $\begin{array}{l}\text { Moderate to strong } \\
\text { integration between FRM } \\
\text { interventions and moderate } \\
\text { with sector-specific } \\
\text { interventions. } \\
\text { Some FRM interventions } \\
\text { capture multiple benefits and } \\
\text { manage trade-offs (on } \\
\text { project basis). } \\
\text { Cost/time efficiencies gained } \\
\text { across FRM and sector- } \\
\text { specific interventions. }\end{array}$ \\
\hline $\begin{array}{l}\text { Low } \\
\text { integration }\end{array}$ & $\begin{array}{l}\text { Moderate bonding, and } \\
\text { moderate to weak bridging } \\
\text { and linking relationships. } \\
\text { Mind-sets starting to align } \\
\text { (willingness is growing, } \\
\text { understanding of } \\
\text { importance to work jointly } \\
\text { but focus on own interests). } \\
\text { Mixed communication } \\
\text { intensity (varied frequency } \\
\text { and quality). }\end{array}$ & $\begin{array}{l}(-/+) \text { Some actor-based } \\
\text { mechanisms in place (e.g., } \\
\text { focal points, meetings) with } \\
\text { varied effectiveness. } \\
\text { (+/-) Some rules present } \\
\text { but often poorly designed } \\
\text { or enforced. } \\
\text { (+/-) Some funding } \\
\text { mechanisms but no joint- } \\
\text { funding and difficult to } \\
\text { combine funding sources. }\end{array}$ & $\begin{array}{l}\text { Moderate presence of } \\
\text { knowledge (e.g., } \\
\text { assessments, studies, } \\
\text { datasets), some } \\
\text { developed jointly by a } \\
\text { variety of actors but } \\
\text { often not shared, and } \\
\text { limited use to influence } \\
\text { other elements. }\end{array}$ & $\begin{array}{l}\text { No joint plans. } \\
\text { Moderate alignment } \\
\text { between different FRM } \\
\text { plans (sources flood risk, } \\
\text { temporal scale, spatial } \\
\text { boundaries) but some } \\
\text { FRM plans may not exist. } \\
\text { Moderate to weak } \\
\text { alignment between } \\
\text { different FRM plans and } \\
\text { sector-specific plans. }\end{array}$ & $\begin{array}{l}\text { Moderate integration } \\
\text { between FRM interventions } \\
\text { and moderate to weak with } \\
\text { sector-specific interventions. } \\
\text { Piloting multibenefit } \\
\text { interventions. } \\
\text { Most trade-offs managed. } \\
\text { Efficiencies delivered for } \\
\text { "easy wins." }\end{array}$ \\
\hline $\begin{array}{l}\text { Minimal } \\
\text { integration }\end{array}$ & $\begin{array}{l}\text { Moderate to weak bonding, } \\
\text { and weak bridging and } \\
\text { linking relationships. } \\
\text { Different mind-sets (siloed } \\
\text { organizational culture, } \\
\text { poor willingness to work } \\
\text { together: "someone else's } \\
\text { problem"). } \\
\text { Poor communication } \\
\text { intensity (low frequency } \\
\text { and only one-way). }\end{array}$ & $\begin{array}{l}\text { (-/+) Only basic actor- } \\
\text { based mechanisms in place } \\
\text { (e.g., conferences, bilateral } \\
\text { meetings) but poor } \\
\text { effectiveness. } \\
\text { (-) Some rules present but } \\
\text { poorly designed and } \\
\text { enforced. } \\
\text { (-) Poor availability of } \\
\text { funding mechanisms. }\end{array}$ & $\begin{array}{l}\text { Moderate to weak } \\
\text { presence of knowledge, } \\
\text { mostly not developed } \\
\text { jointly, shared across } \\
\text { actors, or effectively } \\
\text { used to influence other } \\
\text { elements. }\end{array}$ & $\begin{array}{l}\text { No joint plans. } \\
\text { Weak alignment of } \\
\text { different FRM plans and/ } \\
\text { or lack of availability. } \\
\text { Weak alignment between } \\
\text { FRM and sector-specific } \\
\text { plans. }\end{array}$ & $\begin{array}{l}\text { Weak integration of FRM } \\
\text { and sector-specific } \\
\text { interventions. } \\
\text { No multiple benefits } \\
\text { captured. } \\
\text { Conflicts/negative side- } \\
\text { effects not managed. } \\
\text { Inefficient implementation. }\end{array}$ \\
\hline
\end{tabular}

to situations in the past where the key FRM actors did not have a shared understanding of FRM, limited interaction, and conflicts were prolonged in projects. For example, the relationship between the EA and IDBs was identified as having significantly improved through increased communication, organizational leadership and availability of positively influencing rule-based mechanisms, e.g., public sector cooperation agreements.

\section{APPLICABILITY OF THE FRAMEWORK}

This framework offers an approach to assess the governance capacity and realization of integration for a specific challenge, and to identify the degree of integration. The framework can be used in different ways. It can be used to identify the overall degree of integration by understanding each element's contribution and their interaction with one another. Additionally, it can be used for a more detailed assessment of the strength of a specific element using the identified indicators and then to reflect back on the influence with other elements.

Another positive feature of the framework is the ability to pinpoint elements that can be improved to reach a higher degree of integration. This can be useful if improvements are planned 
for a specific element, to identify how other elements could additionally be improved. In particular, the focus on improving integration is often on developing plans or implementing projects, but using the framework can help to ensure that the governance capacity for integration is also addressed or that its influences are considered when approaching the integration improvements. For example, an intervention, such as an EA-led flood scheme, transport scheme, or NFM scheme, can be assessed to understand its influence on the development of relationships and if any mechanisms supported or hindered its ability to reach a high degree of integration. On the other hand, improvements may focus on improving the capacity for integration through building relationships or improving mechanisms, and the framework helps bring to the forefront the interconnectivity between this and the realization of integration in practice, for example, how relationships between developers, planning authorities, and LLFAs, are enabling or hindering the realization of integration through the delivery of risk-informed housing developments.

The framework is flexible in that it can be used for a range of different integration challenges within FRM, which may evolve in stages depending on interests and priorities. The degree of integration can be assessed between different FRM strategies, sources of flood risk, and at different spatial boundaries, e.g., administrative, catchment, or geographical. It can specifically assess integration between FRM and other sectors, such as agriculture or emergency response. Additionally, the framework could be applied to assess past, current, or future scenarios of integration challenges. Although the framework was developed based on evidence from FRM in England, it is expected that it can be applied to other countries and their associated flood risk governance contexts. Although the integration challenges may vary from one country to another, it is expected that the elements and associated indicators will still be applicable. However, the appropriateness of some mechanisms are likely to vary. Furthermore, given the varied nature of integration challenges across different countries and their FRM governance contexts, we are apprehensive to use the framework to directly compare integration across countries because these could be misinterpreted. Nevertheless, we still recommend comparisons but only with a clear statement of the integration context. It is anticipated that the framework could also be used for integration challenges wider than FRM (or for other wicked problems), however the framework would need some adjustments and testing to do so.

\section{CONCLUSIONS}

The nature of managing flood risk across multiple policy and implementation settings is complex, whereby some degree of integration is necessary to enable better outcomes for flood risk management (FRM) and sector-specific goals. We propose a framework for assessing integration in FRM, as developed on the basis of a literature review and supported by evidence on FRM in England. The framework specifies the importance of identifying the integration challenge, assessing the governance capacity for integration, through the strength of actor relationships and influencing mechanisms, and the realization of integration through knowledge, policies, and interventions. The framework comprises a simple assessment table to identify the degree of integration (high, intermediate, low, or minimal) for a specific integration challenge. The framework offers flexibility, and it can be applied simply to get a general positioning of the degree of integration, but also in-depth to assess specific elements and to establish how they interact with others. The framework can be used to assess multiple integration challenges within FRM, e.g., across specific sectors, spatial boundaries, or FRM strategies.

The framework emphasizes the interconnectedness between two dimensions of integration: building governance capacity for integration and realizing integration in practice. The governance capacity for integration demonstrates the importance of building strong relationships between key FRM actors (bonding), sectorspecific actors (bridging), and communities (linking), and understanding the positive and/or negative influence of actor-, rule-, and resource-based mechanisms. Realizing integration in practice is approached from FRM and sector-specific perspectives, with the aim to reduce conflicts across sectors and fully maximize opportunities for synergies. Furthermore, the research on FRM in England showed that working toward integration is an evolving process where stepwise changes to different dimensions and elements are expected over time rather than any "quick fixes."

The framework provides theoretical progression on the concept of integration and how it can be assessed. Further research on the framework is recommended to test detailed applications for different geographical and flood risk governance contexts. Such research can help to understand the interactions and influences between elements of the capacity and realization of integration, and help to better characterize the different degrees of integration. Additionally, the influence of other external factors on integration should be explored, such as flood events and socioeconomic conditions. Ultimately, such an assessment of integration should help researchers, policy makers, and practitioners work toward an improved degree of integration in FRM.

Responses to this article can be read online at: http://www.ecologyandsociety.org/issues/responses. php/11298

\section{Acknowledgments:}

System-Risk ETN project, funded under the EU's Framework Programme for Research and Innovation Horizon 2020 (Grant Agreement No. 676027). The authors thank Professor Edmund C. Penning-Rowsell and the two reviewers for their constructive comments about this paper.

\section{LITERATURE CITED}

Agranoff, R. 2006. Inside collaborative networks: ten lessons for public managers. Public Administration Review 66:56-65. https:// doi.org/10.1111/j.1540-6210.2006.00666.X

Agranoff, R., and M. McGuire. 2003. Inside the matrix: integrating the paradigms of intergovernmental and network management. International Journal of Public Administration 26 (12):1401-1422. https://doi.org/10.1081/PAD-120024403 
Alexander, M., S. Priest, and H. Mees. 2016. A framework for evaluating flood risk governance. Environmental Science and Policy 64:38-47. https://doi.org/10.1016/j.envsci.2016.06.004

Anselmo, V., G. Galeati, S. Palmieri, U. Rossi, and E. Todini. 1996. Flood risk assessment using an integrated hydrological and hydraulic modelling approach: a case study. Journal of Hydrology 175:533-554. https://doi.org/10.1016/S0022-1694(96)80023-0

Arts, B., P. Leroy, and J. van Tatenhove. 2006. Political modernisation and policy arrangements: a framework for understanding environmental policy change. Public Organization Review 6(2):93-106. https://doi.org/10.1007/s11115-006-0001-4

Associated Programme on Flood Management (APFM). 2017. Selecting measures and designing strategies for integrated flood management - a guidance document. Associated Programme on Flood Management.

Benson, D., I. Lorenzoni, and H. Cook. 2016. Evaluating social learning in England flood risk management: an individualcommunity interaction' perspective. Environmental Science \& Policy 55:326-334. https://doi.org/10.1016/j.envsci.2015.05.013

Brown, J. D., and S. L. Damery. 2002. Managing flood risk in the UK: towards an integration of social and technical perspectives. Transactions of the Institute of British Geographers 27:412-426. https://doi.org/10.1111/1475-5661.00063

Candel, J. J. L., and R. Biesbroek. 2016. Toward a processual understanding of policy integration. Policy Sciences 49 (3):211-231. https://doi.org/10.1007/s11077-016-9248-y

Challies, E., J. Newig, T. Thaler, E. Kochskämper, and M. LevinKeitel. 2016. Participatory and collaborative governance for sustainable flood risk management: an emerging research agenda. Environmental Science \& Policy 55:275-280. https://doi. org/10.1016/j.envsci.2015.09.012

Department for Environment, Food \& Rural Affairs (Defra). 2017. Schemes across the country to receive $£ 15$ million of natural floodmanagement funding. Defra, London, UK. https://www.gov. uk/government/news/schemes-across-the-country-to-receive-15-millionof-natural-flood-management-funding

Eggenberger, M., and M. R. Partidário. 2000. Development of a framework to assist the integration of environmental, social and economic issues in spatial planning. Impact Assessment and Project Appraisal 18(3):201-207. https://doi.org/10.3152/147154$\underline{600781767448}$

Emerson, K., T. Nabatchi, and S. Balogh. 2012. An integrative framework for collaborative governance. Journal of Public Administration Research and Theory 22(1):1-29. https://doi. org/10.1093/jopart/mur011

Environment Agency. 2012. Principles for implementing flood and coastal resilience funding partnerships. Environment Agency, Bristol, UK.

Environment Agency. 2016. Reducing flood risk from source to sea. First steps toward an integrated catchment plan for Cumbria. Environment Agency, Bristol, UK.

Environment Agency. 2017. Working with natural processes to reduce flood risk. Environment Agency, Bristol, UK. [online]
URL: https://www.gov.uk/government/publications/working-withnatural-processes-to-reduce-flood-risk

Environment Agency. 2019. Draft national flood and coastal erosion risk management strategy for England. Environment Agency, Bristol, UK.

Evers, M., A. Jonoski, Č. Maksimovič, L. Lange, S. Ochoa Rodriguez, A. Teklesadik, J. Cortes Arevalo, A. Almoradie, N. Eduardo Simões, L. Wang, and C. Makropoulos. 2012. Collaborative modelling for active involvement of stakeholders in urban flood risk management. Natural Hazards and Earth System Science 12(9):2821-2842. https://doi.org/10.5194/ nhess-12-2821-2012

Fereday, J., and E. Muir-Cochrane. 2006. Demonstrating rigor using thematic analysis: a hybrid approach of inductive and deductive coding and theme development. International Journal of Qualitative Methods 5(1):80-92. https://doi.org/10.1177/160940690600500107

Forino, G., J. von Meding, and G. J. Brewer. 2015. A conceptual governance framework for climate change adaptation and disaster risk reduction integration. International Journal of Disaster Risk Science 6(4):372-384. https://doi.org/10.1007/ s13753-015-0076-Z

Foster-Fishman, P. G., D. A. Salem, N. A. Allen, and K. Fahrbach. 2001. Facilitating interorganizational collaboration: the contributions of interorganizational alliances. American Journal of Community Psychology 29(6):875-905. https://doi. org/10.1023/A:1012915631956

Freude am Fluss. 2007. Freude am Fluss: an innovative approach to river management. Freude am Fluss, Nijmegen, The Netherlands.

Gilissen, H. K., M. Alexander, J. C. Beyers, P. Chmielewski, P. Matczak, T. Schellenberger, and C. Suykens. 2015. Bridges over troubled waters: an interdisciplinary framework for evaluating the interconnectedness within fragmented domestic flood risk management systems. Journal of Water Law 25(1):12-26.

Gittell, R. J., and A. Vidal. 1998. Community organizing: building social capital as a development strategy. SAGE, Thousand Oaks, California, USA.

Glasbergen, P., and F. Klijn. 1991. Integrated water and wetland management: towards a project approach. Landscape and Urban Planning 20:257-262. https://doi.org/10.1016/0169-2046(91)90119-7

Global Water Partnership (GWP). 2000. Integrated water resources management. Global Water Partnership Technical Advisory Committee, Stockholm, Sweden.

Granovetter, M. S. 1973. Weak ties. American Journal of Sociology 78(6):1360-1380.

Hall, J. W., P. B. Sayers, M. J. A. Walkden, and M. Panzeri. 2006. Impacts of climate change on coastal flood risk in England and Wales: 2030-2100. Philosophical Transactions of the Royal Society A: Mathematical, Physical and Engineering Sciences 364:1027-1049. https://doi.org/10.1098/rsta.2006.1752

Hay, C. 1995. Structure and agency. Pages 189-206 in G. Stoker and D. Marsh, editors. Theory and methods in political science. Macmillan, London, UK. https://doi.org/10.1007/978-1-349-24106-4 11 
Head, B. 2008. Wicked problems in public policy. Public Policy 3 (2):101.

Hegger, D. L. T., P. P. J. Driessen, M. Wiering, H. F. M. W. van Rijswick, Z. W. Kundzewicz, P. Matczak, A. Crabbé, G. T. Raadgever, M. H. N. Bakker, S. J. Priest, C. Larrue, and K. Ek. 2016. Toward more flood resilience: Is a diversification of flood risk management strategies the way forward? Ecology and Society 21 (4):52. https://doi.org/10.5751/ES-08854-210452

HM Government. 2018. A green future: our 25 year plan to improve the environment. Defra, London, UK

Hooijer, A., F. Klijn, G. B. M. Pedroli, and A. G. van Os. 2004. Towards sustainable flood risk management in the Rhine and Meuse river basins: synopsis of the findings of IRMA-SPONGE. River Research and Applications 20(3):343-357. https://doi. org/10.1002/rra.781

Keast, R., K. Brown, and M. Mandell. 2007. Getting the right mix: unpacking integration meanings and strategies. International Public Management Journal 10(1):9-33. https://doi. org/10.1080/10967490601185716

Klijn, F., and T. Schweckendiek, editors. 2013. Comprehensive floodrisk management: research for policy and practice. CRC, Boca Raton, Florida, USA. https://doi.org/10.1201/b13715

Koop, S. H. A., L. Koetsier, A. Doornhof, O. Reinstra, C. J. Van Leeuwen, S. Brouwer, C. Dieperink, and P. P. J. Driessen. 2017. Assessing the governance capacity of cities to address challenges of water, waste, and climate change. Water Resources Management 31(11):3427-3443. https://doi.org/10.1007/s11269-017-1677-7

McNamara, M. 2012. Starting to untangle the web of cooperation, coordination, and collaboration: a framework for public managers. International Journal of Public Administration 35:389-401. https://doi.org/10.1080/01900692.2012.655527

Ministry of Housing, Communities and Local Government (MHCLG). 2019. The Oxford-Cambridge arc: government ambition and joint declaration between government and local partners. MHCLG, London, UK.

Network Rail. 2017. Weather resilience and climate change adaptation strategy 2017-2019. Network Rail, London, UK.

Newig, J., and O. Fritsch. 2009. Environmental governance: participatory, multi-level - and effective? Environmental Policy and Governance 19(3):197-214. https://doi.org/10.1002/eet.509

Organisation for Economic Co-operation and Development (OECD). 2015. Framework for policy coherence for sustainable development: a self-assessment tool to design, implement and track progress on mutually supportive policies for sustainable development. OECD, Paris, France

Ostrom, E. 2010. Beyond markets and states: polycentric governance of complex economic systems. American Economic Review 100(3):641-672. https://doi.org/10.1257/aer.100.3.641

Park, J., T. P. Seager, P. S. C. Rao, M. Convertino, and I. Linkov. 2013. Integrating risk and resilience approaches to catastrophe management in engineering systems. Risk Analysis 33(3):356-367. https://doi.org/10.1111/j.1539-6924.2012.01885.X

Parkes, M. W., K. E. Morrison, M. J. Bunch, L. K. Hallström, R. C. Neudoerffer, H. D. Venema, and D. Waltner-Toews. 2010.
Towards integrated governance for water, health and socialecological systems: the watershed governance prism. Global Environmental Change 20(4):693-704. https://doi.org/10.1016/j. gloenvcha.2010.06.001

Pattberg, P., and O. Widerberg. 2016. Transnational multistakeholder partnerships for sustainable development: conditions for success. Ambio 45(1):42-51. https://doi. org/10.1007/s13280-015-0684-2

Putnam, R. D. 2000. Bowling alone: the collapse and revival of American community. Simon and Schuster Paperbacks, New York, New York, USA.

Reed, M. S., A. Graves, N. Dandy, H. Posthumus, K. Hubacek, J. Morris, C. Prell, C. H. Quinn, and L. C. Stringer. 2009. Who's in and why? A typology of stakeholder analysis methods for natural resource management. Journal of Environmental Management 90(5):1933-1949. https://doi.org/10.1016/j. jenvman.2009.01.001

Renn, O. 2008. Risk governance: coping with uncertainty in a complex world. Routledge, London, UK. https://doi. org/10.4324/9781849772440

Russel, D., J. Turnpenny, and A. Jordan. 2018. Mainstreaming the environment through appraisal: integrative governance or logics of disintegration? Environment and Planning C: Politics and Space 36(8):1355-1370. https://doi.org/10.1177/2399654418767656

Samuels, P., M. Morris, P. Sayers, J. Creutin, A. Kortenhaus, F. Klijn, A. Van Os, and J. Schanze. 2010. A framework for integrated flood risk management. 1st IAHR European Division Congress. International Association for Hydro-Environment Engineering and Research.

Sayers, P., G. Galloway, E. C. Penning-Rowsell, L. Yuanyuan, S. Fuxin, C. Yiwei, W. Kang, T. Le Quesne, L. Wang, Y. Guan, T. Le Quesne, L. Wang, and Y. Guan. 2014. Strategic flood management: ten 'golden rules' to guide a sound approach. International Journal of River Basin Management 13(2):137-151. https://doi.org/10.1080/15715124.2014.902378

Stafford-Smith, M., D. Griggs, O. Gaffney, F. Ullah, B. Reyers, N. Kanie, B. Stigson, P. Shrivastava, M. Leach, and D. O'Connell. 2017. Integration: the key to implementing the Sustainable Development Goals. Sustainability Science 12(6):911-919. https:// doi.org/10.1007/s11625-016-0383-3

Stead, D. 2008. Institutional aspects of integrating transport, environment and health policies. Transport Policy 15:139-148. https://doi.org/10.1016/j.tranpol.2007.12.001

Surridge, B., and B. Harris. 2007. Science-driven integrated river basin management: a mirage? Interdisciplinary Science Reviews 32(3):298-312. https://doi.org/10.1179/030801807x211711

Szreter, S., and M. Woolcock. 2004. Health by association? Social capital, social theory, and the political economy of public health. International Journal of Epidemiology 33(4):650-667. https://doi. org/10.1093/ije/dyh013

Thissen, W. A. H., and W. E. Walker. 2012. Public policy analysis: new developments. Springer, New York, New York, USA.

UK Government. 2010. Flood and Water Management Act. UK Government, London, UK. 
Underdal, A. 1980. Integrated marine policy. What? Why? How? Marine Policy 4(3):159-169. https://doi.org/10.1016/0308-597X (80)90051-2

UNISDR. 2015. Making development sustainable: the future of disaster risk management. Global Assessment Report on Disaster Risk Reduction. United Nations Office for Disaster Risk Reduction, Geneva, Switzerland. https://doi.org/10.18356/ bd3a73ea-en

van den Hove, S. 2007. A rationale for science-policy interfaces. Futures 39:807-826. https://doi.org/10.1016/j.futures.2006.12.004

van Herk, S., J. Rijke, C. Zevenbergen, and R. Ashley. 2015. Understanding the transition to integrated flood risk management in the Netherlands. Environmental Innovation and Societal Transitions 15:84-100. https://doi.org/10.1016/j.eist.2013.11.001

van Herk, S., C. Zevenbergen, R. Ashley, and J. Rijke. 2011. Learning and action alliances for the integration of flood risk management into urban planning: a new framework from empirical evidence from The Netherlands. Environmental Science and Policy 14(5):543-554. https://doi.org/10.1016/j.envsci.2011.04.006

Visseren-Hamakers, I. J. 2015. Integrative environmental governance: enhancing governance in the era of synergies. Current Opinion in Environmental Sustainability 14:136-143. https://doi. org/10.1016/j.cosust.2015.05.008

Walker, G., F. Tweed, and R. Whittle. 2014. A framework for profiling the characteristics of risk governance in natural hazard contexts. Natural Hazards and Earth System Sciences 14 (1):155-164. https://doi.org/10.5194/nhess-14-155-2014

Williams, P. 2011. The life and times of the boundary spanner. Journal of Integrated Care 26(1):17-32.

Williams, P., and H. Sullivan. 2009. Faces of integration. International Journal of Integrated Care 9(4):1-13. https://doi. org/10.5334/ijic.509

Woods-Ballard, B., S. Wilson, H. Udale-Clarke, S. Illman, T. Scott, R. Ashley, and R. Kellagher. 2015. The SuDS manual. CIRIA, London, UK. London.

World Meteorological Organization (WMO). 2009. Integrated flood management concept paper. WMO, Geneva, Switzerland. 